\title{
POLÍTICA NACIONAL DE REFORMA AGRÁRIA E SEUS DIFERENTES INSTRUMENTOS FUNDIÁRIOS ${ }^{1}$
}

\author{
Ana Luisa Santos Rocha* \\ José Heder Benatti**
}

Resumo: O presente artigo tem como objetivo expor os diferentes instrumentos que compõem o rol de projetos da reforma agrária no Brasil. A análise é feita a partir da Norma de Execução INCRA $n^{\circ}$. 69, de 12 de março de 2008, que dispõe sobre o processo de criação e reconhecimento de projetos de assentamento de reforma agrária. São apresentados ainda, os projetos estaduais no Estado do Pará. Parte-se do pressuposto de que a atual política de reforma agrária, sobretudo em razão do II Plano Nacional lançado em 2003, aumentou gradativamente as categorias fundiárias e os sujeitos abrangidos nessa política pública.

Palavras-Chave: Reforma Agrária; Instrumentos Fundiários; Amazônia; Assentamentos Tradicionais e Diferenciados; Projetos Reconhecidos.

\section{NATIONAL AGRARIAN REFORM POLICY AND ITS DIFFERENT LAND INSTRUMENTS}

\begin{abstract}
The present paper aims to expose the different instruments that compose the list of agrarian reform projects in Brazil. The analysis is performed based on the Standard of Execution INCRA number 69, from March 12 of 2008, that treats about the creation process and acknowledgment of agrarian reform settlement projects. State projects in the State of Pará are also presented. It follows from the assumption that the current agrarian reform policy, mainly due to the II National Plan released in 2003, has gradually increased the land categories and the subjects covered in this public policy.
\end{abstract}

Keywords: Agrarian Reform, Land Instruments, Amazon, Traditional and Differentiated Settlements, Acknowledged Projects

\footnotetext{
${ }^{1} \mathrm{O}$ debate exposto no presente artigo faz parte das discussões desenvolvidas na dissertação de Mestrado defendida em 2016 no Programa de Pós-Graduação em Direito da Universidade Federal do Pará pela Mestre Ana Luisa Santos Rocha, sob orientação do Prof. Dr. José Heder Benatti, intitulada "Reforma Agrária na Amazônia: novas tendências, novos sujeitos e grandes desafios".

* Doutoranda e Mestra em Direito pelo Programa de Pós-Graduação em Direito da Universidade Federal do Pará. Professora Substituta de Direito na mesma Instituição. Advogada voluntária na Clínica de Direitos Humanos da Amazônia (CIDHA/UFPA). E-mail: analuisasrocha@gmail.com.

** Mestre em Direito e Doutor em Ciência e Desenvolvimento Socioambiental pelo Núcleo de Altos Estudos Amazônicos da Universidade Federal do Pará, Professor da Graduação, da Pós-Graduação em Direito da UFPA e Membro da Clínica de Direitos Humanos da Amazônia (CIDHA/UFPA). Pesquisador do CNPq. Diretor do Instituto de Ciências Jurídicas da UFPA. E-mail: jbenatti@ufpa.br.
} 


\section{INTRODUÇÃO}

Não há dúvidas quanto à previsão no ordenamento jurídico brasileiro de diversos instrumentos, que mesmo com naturezas jurídicas distintas, como é o caso de unidades de conservação de uso sustentável, projetos de assentamento e propriedade quilombola, garantem o acesso a direitos territoriais a agricultores familiares e povos tradicionais (BENATTI, 2011).

Nessa perspectiva o II Plano Nacional de Reforma Agrária (PNRA), lançado em 2003, trouxe como público, dentre outros, os trabalhadores rurais sem-terra, os atuais assentados, setores da agricultura familiar, posseiros, populações ribeirinhas, comunidades quilombolas e extrativistas (BRASIL, 2005, p. 17). De acordo com o plano, os diversos segmentos sociais seriam objeto de "instrumentos diferenciados e apropriados às suas especificidades e às características de cada região" (BRASIL, 2005, p. 17).

O escopo do presente artigo é apresentar, caracterizar e destacar os principais aspectos desses diversos instrumentos que hoje fazem parte do PNRA, apesar das particularidades de cada um. São instrumentos que reconhecem, ora a posse, ora a propriedade, seja através de titulações individuais de famílias ou que considerem o aspecto coletivo de uma comunidade, destinados a um público também diferenciado como camponeses, agricultores, posseiros e povos tradicionais.

Tais instrumentos surgiram a partir de contextos históricos específicos e com fundamentações distintas como, por exemplo: organizar o processo de ocupação territorial do país, incentivar o povoamento de regiões consideradas remotas (LIMA, 1975, p. 77), apaziguar conflitos por terra (BERGAMASCO; NORDER, 1996, p. 9), criar espaços de proteção ambiental aliados ao direito territorial de povos tradicionais (MENEZES, 2011, p. 345), e ainda, para responder às fortes demandas dos movimentos sociais que lutam pelo direito de acesso à terra (SAUER, 2005, p. 59).

Como o corte utilizado na presente pesquisa diz respeito aos instrumentos utilizados e reconhecidos pelo poder público como reforma agrária, são eles que serão expostos, em conformidade com a Norma de Execução INCRA n ${ }^{\circ}$. 69, de 12 de março de 2008, que dispõe sobre o processo de criação e reconhecimento de projetos de assentamento de reforma agrária.

Os projetos de reforma agrária englobam, atualmente, os criados por meio de obtenção de terras pelo INCRA, na forma tradicional, conhecidos como Projeto de Assentamento (PA), os ambientalmente diferenciados, como Projeto de Assentamento Agroextrativista (PAE), Projeto de Desenvolvimento Sustentável (PDS) e o Projeto de Assentamento Florestal (PAF) e os Projetos de Assentamentos Especiais Quilombolas (PA Especial). 
O segundo grupo de projetos de reforma agrária são aqueles reconhecidos pelo INCRA, cuja criação cabe a outras esferas do poder público para acesso às políticas públicas do programa de reforma agrária. Nesse rol, incluem-se as Reservas Extrativistas (RESEX), as Reservas de Desenvolvimento Sustentável (RDS), as Florestas Nacionais (FLONA), os Territórios Quilombolas e os projetos criados na esfera estadual e municipal, como assentamentos estaduais, territórios quilombolas estaduais, RESEX estaduais, dentre outros.

Também integram as categorias reconhecidas pelo INCRA, os Assentamentos Municipais (PAM), os Assentamentos criados a partir do Programa Nacional de Crédito Fundiário (PCT), as áreas de Reconhecimento de Assentamento de Fundo de Pasto (PFP) e os Reassentamentos de Barragem (PRB).

Na Amazônia Legal, a configuração espacial dessas várias categorias territoriais, que juntas correspondem a mais de 3.000 projetos $^{2}$, incluindo assentamentos tradicionais, assentamentos diferenciados e áreas já reconhecidas pelo INCRA como RDS, RESEX, FLONA e assentamentos estaduais.

Serão assim, traçados os principais aspectos históricos, sociais e jurídicos de consolidação e utilização desses instrumentos pelo Poder Público no atendimento das demandas das comunidades rurais, com foco para a Amazônia e para o Estado do Pará.

\section{ASSENTAMENTOS TRADICIONAIS}

A criação de assentamentos é uma ação que sempre esteve diretamente ligada à política de reforma agrária. Esse termo se fez presente na literatura jurídica e sociológica desde 1960 com a reforma agrária venezuelana (BERGAMASCO; NORDER, 1996, p. 9).

Os projetos de assentamento são espaços geográficos que congregam famílias beneficiárias das ações de reforma agrária (SAUER, 2005, p. 59). Via de regra, esses projetos se formalizam a partir de um processo de desapropriação de um imóvel rural privado, atrelado às fortes lutas sociais pela redistribuição da terra (CARVALHO, 1999, p. 5).

$\mathrm{Na}$ análise sobre os assentamentos destaca-se a conversão de um latifúndio, enquanto grande área de terra improdutiva, em lugar de produção, de trabalho e de vida para dezenas de famílias (SAUER, 2005, p. 95), sendo o assentamento a constituição de "uma nova organização econômica, política, social e ambiental naquela área, com a posse da terra por uma

2 Dados retirados da plataforma I3Geo de acervo fundiário do INCRA. Disponível em: <http://acervofundiario.incra.gov.br/i3geo/interface/incra.html?6r8chko9cbvehi9rmvdqpctl10>. Acesso em 19 mai 2017.

Rev. de Direito Agrário E Agroambiental | e-ISSN: 2526-0081| Brasília | v. 3 | n. 1 | p. 78 - 96 | Jan/Jun. 2017 
heterogeneidade social de famílias de trabalhadores rurais sem terra" (CARVALHO, 1999, p. $5)$.

Nessa mesma linha, o INCRA, que é a entidade federal responsável pela execução das ações de reforma agrária no Brasil, define o assentamento rural como um conjunto de unidades agrícolas independentes entre si, instaladas onde originalmente existia um imóvel rural que pertencia a um único proprietário ${ }^{3}$.

Bergamasco e Norder (1996, p. 7) conceituam os assentamentos da seguinte forma:

De uma forma genérica, os assentamentos rurais podem ser definidos como a criação de novas unidades de produção agrícola, por meio de políticas governamentais visando o reordenamento do uso da terra, em benefício de trabalhadores rurais sem terra ou com pouca terra. Como o seu significado remete à fixação do trabalhador na agricultura, envolve também a disponibilidade de condições adequadas para o uso da terra e o incentivo à organização social e à vida comunitária.

Em geral, o assentamento ocorre quando o imóvel adquirido não tem possuidor (ROCHA et. al., 2015, p. 194). Por essa concepção, os projetos de regularização fundiária e de reforma agrária seriam diferentes porque aquela pressupõe a prévia posse, a qualquer título, do indivíduo a ser beneficiado. Na reforma agrária, por sua vez, o imóvel estaria desocupado e servindo de base territorial para o assentamento (ROCHA et. al., 2015, p. 194).

A criação de assentamentos de trabalhadores rurais foi institucionalizada no país desde 1964 com o Estatuto da Terra (BRASIL. Lei nº. 4.504/1964). Atualmente, possui fundamento constitucional no art. 184 que dispõe sobre a desapropriação por interesse social para fins de reforma agrária do imóvel rural que não cumpre sua função social, cuja competência é da União, através do INCRA.

Ademais, é comando constitucional a destinação de terras públicas e devolutas para a reforma agrária. A Lei $\mathrm{n}^{\circ}$. 8.629/93 que regulamenta os dispositivos constitucionais relativos à reforma agrária também compõe o rol de normas que fundamentam e orientam a criação de assentamentos no país.

Embora previstas no ordenamento jurídico desde o Estatuto da Terra, as políticas voltadas para a criação de assentamentos em áreas oriundas de processos desapropriatórios não foram colocadas em prática durante o Governo Militar (GRAZIANO NETO, 1998, p. 154). Deu-se prioridade para a criação de projetos de colonização públicos e particulares respaldados também no Estatuto da Terra $^{4}$ - que objetivavam a ocupação dos vazios demográficos do país (LIMA, 1975, p. 77).

\footnotetext{
${ }^{3}$ Definição disponível em: <http://www.incra.gov.br/assentamento>. Acesso em 19 mai 2017.

${ }^{4}$ Nos termos do art. $4^{\circ}$, IX do Estatuto, a colonização é definida como toda a atividade oficial ou particular, que se destine a promover o aproveitamento econômico da terra, pela sua divisão em propriedade familiar ou através
} 
Foi sob a égide da redemocratização que a criação de assentamentos da reforma agrária intensificou-se nos últimos governos. No contexto pós-ditadura, em 1985, o governo de José Sarney lançou o Primeiro Plano Nacional de Reforma Agrária. Dezoito anos depois, em novembro de 2003, durante o primeiro Governo Lula foi lançado o II Plano Nacional de Reforma Agrária.

Segundo números oficiais do Instituto Nacional de Colonização e Reforma Agrária (INCRA) $)^{5}$, durante os oito anos (1995 a 2002) em que Fernando Henrique Cardoso ocupou a Presidência, mais de 500 mil famílias de trabalhadores rurais foram assentadas no Brasil. De 2003 a 2010, no Governo Lula, foram mais de 600 mil famílias assentadas ${ }^{6}$. Em ambos os governos o destaque da criação de projetos de assentamento foi a Amazônia (LE TOURNEAU; BURSZTYN, 2010, p. 116). No primeiro Governo Dilma (2011-2014) foram assentadas 83.174 famílias.

Nos termos da Lei nº 8.629/93, na obtenção de terras rurais destinadas à implantação dos projetos de assentamento para o programa de reforma agrária são exigidos previamente estudos sobre a viabilidade econômica ${ }^{7}$ e a potencialidade de uso dos recursos naturais da área (art. 17, I). Os projetos são criados pela Superintendência Regional do INCRA competente, através de portarias publicadas no Diário Oficial da União ${ }^{8}$.

Segundo o art. 17, IV do citado diploma legal, a clientela dos projetos de assentamento de reforma agrária é integrada por aqueles que satisfizerem os requisitos para seleção e classificação, bem como as demais exigências contidas na lei ${ }^{9}$.

Isso se materializa através da Relação de Beneficiários da Reforma Agrária, cuja inscrição e cadastro de candidatos tem caráter nacional, sendo o processo de seleção realizado

de Cooperativas. Em razão das duras críticas sofridas pela política de colonização da década de 1970 em razão do fracasso desses projetos na Amazônia, trata-se de um instrumento não mais utilizado pelo Poder Público para o acesso à terra de comunidades rurais (ROCHA et. al., 2015, p. 194).

${ }^{5}$ A discussão crítica sobre os números oficiais da reforma agrária divulgados pelo INCRA em sua base de dados será apresentada no terceiro item da dissertação.

${ }^{6}$ Dados oficiais coletados do site do portal do INCRA, na seção de "Números oficiais da Reforma Agrária". Disponível em: <http://www.incra.gov.br/sites/default/files/uploads/reforma-agraria/questao-agraria/reforma agraria/familias_assentadas_serie_historica_incra_mar_2014.p

df>. Acesso em 19 mai 2017.

${ }^{7}$ Sauer (2005, p. 61) chama atenção para a necessidade de uma análise crítica sobre esse ponto, pois não se pode confundir a viabilidade econômica que é uma equação utilizada para avaliar o retorno econômico dos assentamentos, no que tange à produção para o mercado e ao resultado dos investimentos governamentais, com as necessidades e demandas sociais concretas como ocupação, trabalho e renda.

${ }^{8}$ Conforme disposto na Norma de Execução do INCRA n". 69 de 12/03/2008 ( $\operatorname{art} .2^{\circ}, \S 4^{\circ}$, "a") que trata do processo de criação e reconhecimento de projetos de assentamentos da Reforma Agrária.

${ }^{9}$ Os critérios previstos no art. 19 da Lei no $.8 .629 / 93$ para a distribuição de imóveis rurais pela reforma agrária, poderão ser alterados caso o Projeto de Lei de Conversão no. 12/2017, que converte a Medida Provisória $\mathrm{n}^{\circ}$. 759/2016, seja aprovado. 
na área sob jurisdição de cada Superintendência Regional do INCRA, como dispõe a Instrução Normativa do INCRA n ${ }^{\circ} .15$ de 30 de março de 2004.

Nos projetos de assentamentos criados são elaborados os Planos de Desenvolvimento de Assentamento (PDA), que fixam as normas básicas para a implantação e investimentos a serem realizados (art.17, III, Lei $\mathrm{n}^{\circ}$. 8.629/93). O PDA é um instrumento de planejamento elaborado por profissionais de assessoria técnica, social e ambiental (ATES) contratados pelo INCRA, em conjunto com as famílias beneficiárias a partir de diagnósticos que retratam a situação do assentamento em termos físicos, sociais, econômicos, culturais e ambientais ${ }^{10}$.

Nos termos do art. 189 da CF/88, os beneficiários da reforma agrária receberão títulos de domínio ou de concessão de uso inegociáveis pelo prazo de dez anos. Regulamentando esse dispositivo, o art. 18 da Lei $n^{\circ}$. 8.629/93 - cuja nova redação foi dada pela Lei ${ }^{\circ}$. 13.001 de 20 de junho de 2014 - estabelece que a distribuição de imóveis rurais pela reforma agrária far-seá por meio de títulos de domínio, concessão de uso ou concessão de direito real de uso $\mathrm{CDRU}^{11}$.

Os contratos de concessão de uso celebrados com os beneficiários do programa de reforma agrária na implantação do assentamento são gratuitos, inegociáveis, podendo ser firmados de forma individual por assentando, ou ainda coletiva, englobando toda a comunidade assentada, assegurando-se o direito de adquirir título de domínio ou a CDRU (art. 18, §2 $2^{\circ}$ ). Caberá ao beneficiário, individual ou coletivamente, optar pela CDRU (art. 18, $4^{\circ}$ ) ou pelo título de domínio.

\section{ASSENTAMENTOS AMBIENTALMENTE DIFERENCIADOS}

Conforme exposto no tópico anterior, a visão tradicional de um assentamento pressupõe a existência de um imóvel rural improdutivo que após o processo de desapropriação passa a “assentar" novas famílias em lotes agrícolas independentes entre si, constituindo-se assim um novo espaço de organização social e econômica.

\footnotetext{
${ }^{10}$ A Norma de Execução do INCRA n ${ }^{\circ} .39$ de 30/03/2004 (art. $3^{\circ}$, III) define os PDAs como ações permanentes que englobam desde o processo de planejamento da ocupação e utilização racional das áreas de assentamento, no âmbito de cada território, até o seu pleno desenvolvimento, através da efetiva garantia dos serviços básicos de infraestrutura física e social.

${ }^{11}$ A norma faz referência à CDRU instituída pelo art. $7^{\circ}$ do Decreto-Lei $n^{\circ}$. 271, de 28 de fevereiro de 1967: É instituída a concessão de uso de terrenos públicos ou particulares remunerada ou gratuita, por tempo certo ou indeterminado, como direito real resolúvel, para fins específicos de regularização fundiária de interesse social, urbanização, industrialização, edificação, cultivo da terra, aproveitamento sustentável das várzeas, preservação das comunidades tradicionais e seus meios de subsistência ou outras modalidades de interesse social em áreas urbanas.
} 
Entretanto, como analisado na primeira parte e reafirmado em diversos pontos da presente dissertação, a realidade do campesinato brasileiro é muito complexa, com vários grupos sociais lutando pelo acesso à terra através de instrumentos que atendam às suas demandas e aos seus próprios modos de vida.

É nessa seara de discussão que se encaixam os chamados assentamentos ambientalmente diferenciados ${ }^{12}$. A origem dessas modalidades de assentamento, cuja criação em âmbito federal também é de responsabilidade do INCRA, está atrelada às lutas dos diversos segmentos camponeses amazônicos pelo reconhecimento do seu modelo de apossamento e pela proteção ambiental $^{13}$, que juridicamente se expressa no conceito de posse agroecológica, como já visto.

Segundo Menezes (2011, p. 345), desde a década de 1980 foram criados "instrumentos inéditos de reforma agrária, visando atender as especificidades da questão agrária amazônica e a defesa dos povos da floresta, categoria que rompia com termos convencionais como camponês e trabalhador rural".

As demandas dos povos tradicionais por instrumentos específicos de acesso ao território foram fundamentais para compreender a insuficiência dos instrumentos do direito estatal brasileiro como o modelo tradicional de assentamento em lotes agrícolas padronizados, que desconsideram as especificidades ambientais e a diversidade do meio rural brasileiro e o amazônico (BENATTI, 2003B, p. 114).

Em 1987 foram criados na esfera federal os Projetos de Assentamento Extrativistas $(\mathrm{PAE})^{14}$, passando a integrar o Plano Nacional de Reforma Agrária. Nessa modalidade, a lógica que está presente não se associa à atribuição de lotes individuais às famílias para posterior conversão em propriedade, mas trata-se de estabelecer concessões de direito real de uso em benefício das famílias residentes em um imóvel público e inalienável ${ }^{15}$ (BENATTI, 2003B, p. 208).

\footnotetext{
${ }^{12}$ Bergamasco e Norder (1996, p. 40) destacam que os assentamentos extrativistas da região Norte só foram institucionalizados após os conflitos pela posse da terra já terem provocado de derramamento de muito sangue, como o de Chico Mendes.

${ }^{13}$ Segundo Benatti (2003B, p. 210), há entre os pressupostos de criação dos assentamentos ambientalmente diferenciados uma "autocrítica velada na trajetória da reforma agrária e dos projetos de assentamento criados na Amazônia, pois, de certa forma, os assentamentos patrocinados pelo governo federal nos anos 70, até meados de 90, favoreceram a destruição da floresta".

${ }^{14}$ A proposta de criação de dos PAEs foi acolhida pelo INCRA após recusa do Instituto Brasileiro de Desenvolvimento Florestal - IBDF, que era o órgão ambiental da época, "pois havia previsão de implantação desse estatuto territorial mesmo em áreas alteradas (não ambientalmente preservadas) e, portanto, sua administração deveria ficar ao encargo de um órgão de gestão fundiária" (MENEZES, 2011, p. 345).

${ }^{15}$ Tal como asseveram Vieira et. al. (2014, p. 376), o princípio da inalienabilidade das terras constitui-se em garantia contra a venda de lotes individuais, "e portanto contra concentração fundiária nas áreas assim delimitadas, subtraindo-as ao mercado fundiário".
} 
Em 1996, em substituição aos PAE originais, o INCRA criou os Projetos de Assentamento Agroextrativistas (PAE) ${ }^{16}$. Em novembro de 1999 foram institucionalizados os Projetos de Desenvolvimento Sustentável (PDS) ${ }^{17}$ e em 2003 foram criados os Projetos de Assentamento Florestais (PAF) ${ }^{18}$.

Em tais modalidades, embora possuam a designação "assentamento", o que indicaria a ideia de "assentar" quem não habitava determinada área, as famílias são regularizadas, isto é, a prévia posse já exercida pela comunidade será oficialmente reconhecida pelo órgão fundiário. Em se tratando de comunidades tradicionais, eles se constituem em instrumentos que reconhecem os seus modelos próprios de apossamento.

Sob o ponto de vista jurídico, os instrumentos agroextrativistas diferenciam-se dos assentamentos tradicionais por não existir previsão de títulos individuais e definitivos de propriedade, mas sim, a concessão de uso coletivo de responsabilidade das associações de agroextrativistas (MENEZES, 2011, p. 346). A lei determina então, que esses assentamentos são de domínio público, com o uso da terra e dos recursos naturais concedidos aos povos tradicionais (BENATTI, 2011, p. 101).

Logo, são ações que se enquadram na determinação constitucional que exige a compatibilização da destinação de terras públicas com o plano nacional de reforma agrária (art. 188, CF/88). Além disso, são modalidades de acesso à terra em consonância com o art. 189 da $\mathrm{CF} / 88$ e do art. 18 da Lei $n^{\circ}$. 8.629/93 no que tange à previsão de concessões de uso celebrados de forma coletiva.

\section{UNIDADES DE CONSERVAÇÃO: RESERVAS EXTRATIVISTAS, RESERVAS DE DESENVOLVIMENTO SUSTENTÁVEL E FLORESTAS NACIONAIS}

Inseridas no mesmo contexto de questionamentos e enfrentamentos aos modelos de assentamentos tradicionais aplicados na Amazônia que favoreceram a destruição da floresta e o desrespeito aos modos de vida dos camponeses amazônicos, as unidades de conservação representam, atualmente, importantes instrumentos de acesso à terra aos povos tradicionais.

A criação de reservas extrativistas (RESEX) está diretamente ligada à luta dos seringueiros do Acre $^{19}$ durante a década de 1980, sendo considerada a "Reforma Agrária dos

\footnotetext{
${ }^{16}$ Portaria INCRA n ${ }^{\circ} .268$, de 23 de outubro de 1996.

${ }^{17}$ Portaria INCRA n ${ }^{\circ} .477$, de 04 de novembro de 1999.

${ }^{18}$ Portaria INCRA n ${ }^{\circ} .1 .141$, de 19 de dezembro de 2003.

${ }^{19}$ Vale destacar que a inspiração desses movimentos sociais na formulação das propostas de assentamentos e de reservas extrativistas, foram as terras indígenas, em que a propriedade da terra é da União e a posse e o uso dos
} 
Seringueiros" (BENATTI, 2003B, p. 171). Trata-se de um modelo que, da mesma forma como nos assentamentos diferenciados, fez convergir políticas públicas antes dissociadas: reforma agrária e meio ambiente (SANTILLI, 2005, p. 142). Assim, as propostas de reservas extrativistas uniram a questão fundiária com a questão agroecológica, valorizando a base econômica extrativista que não leva ao esgotamento dos recursas naturais (BENATTI, 2003B, p. 172).

Em sua origem, as propostas de RESEX foram consubstanciadas nos projetos de assentamento extrativistas criados pelo INCRA em 1987. Mas foi com a Lei $\mathrm{n}^{\circ}$. 7.804, de 18 de julho de 1989, regulamentada pelo Decreto $n^{\circ} .98 .897$, de 30 de janeiro de 1990, que as reservas passaram a integrar a Política Nacional de Meio Ambiente, saindo da pauta estritamente fundiária. Menezes (2011, p. 346) explica essa institucionalização:

$\mathrm{O}$ ato oficial que criou o PAE significava também a incorporação das Reservas Extrativistas (inserida na categoria PAE) ao Plano Nacional de Reforma Agrária. No entanto, em virtude de morosidade na criação dos PAEs, os seringueiros, através do Conselho Nacional de Seringueiros, criado em 1985 e tendo incorporado o discurso internacional de preservação das florestas, insistiram no formato da Reserva Extrativista como a forma mais eficaz de fazer reforma agrária para os extrativistas. Neste ambiente de intenso debate, o governo legitimou a Reserva Extrativista colocando-a na pauta da política nacional de meio ambiente e institucionalizando-a a partir da criação da Lei $n^{\circ}$. 7.084, de 18 de julho de 1989 e do decreto ${ }^{\circ}$. 98.987, de 30 de janeiro de 1990, onde o IBAMA torna-se responsável pela RESEX, constituindo o Centro Nacional de Desenvolvimento Sustentado das Populações Tradicionais (CNPT) como órgão gestor das reservas.

$\mathrm{Na}$ regulamentação das reservas extrativistas (art. 3º, Decreto $n^{\circ}$. 98.987/90) foi destacado o papel do órgão ambiental federal, o Instituto Brasileiro de Meio Ambiente e dos Recursos Naturais Renováveis (IBAMA) ${ }^{20}$, na criação e gestão das reservas, ao contrário dos assentamentos extrativistas, cuja responsabilidade era do órgão fundiário, o INCRA.

O Decreto regulamentador (art. $4^{\circ}$, Decreto $n^{\circ}$. 98.987/90) estabelecia também que a exploração autossustentável e a conservação dos recursos naturais nas reservas extrativistas seriam reguladas por contrato de concessão de direito real de uso ${ }^{21}$, concedido a título gratuito e incluindo, ainda, o plano de utilização da reserva extrativista.

Atualmente, as reservas extrativistas estão inseridas no Sistema Nacional de Unidades de Conservação da Natureza (SNUC) criado através da Lei no . 9.985, de 18 de julho de 2000, com regulamentação dada pelo Decreto $n^{\circ}$. 4.340, de 22 de agosto de 2002. Na esfera federal,

recursos naturais é coletiva e compartilhada (SANTILLI, 2005, p. 2005), cujo modelo encontra-se constitucionalizado no art. 231, da CF/88.

${ }^{20}$ O IBAMA foi criado em 22 de fevereiro de 1989 através da Lei $\mathrm{n}^{\mathrm{o}}$. 7.735.

${ }^{21}$ Instrumento previsto no art. $7^{\circ}$ do Decreto-Lei $\mathrm{n}^{\mathrm{o}} 271$, de 28 de fevereiro de 1967. 
a criação das unidades de conservação cabe ao Instituto Chico Mendes de Conservação da Biodiversidade (ICMBio), autarquia federal criada em 28 de agosto de 2007, pela Lei $\mathrm{n}^{\circ} .11 .516$.

As RESEX ${ }^{22}$ são classificadas como unidade de conservação de uso sustentável (art. 14), ao lado de outras duas categorias de unidade dispostas nessa norma e que hoje se junta ao rol de instrumentos que possibilitam o acesso à terra às comunidades tradicionais: as reservas de desenvolvimento sustentável ${ }^{23}$ (RDS) e as florestas nacionais ${ }^{24}$ (FLONAS).

Tanto as RESEX, quanto as RDS e as FLONAS, são figuras jurídicas de proteção ambiental que congregam a exploração econômica, distinguindo-se das unidades de conservação de proteção integral cujo foco é a proteção de espécies vegetais e animais. Ao preverem a exploração sustentável e a conservação dos recursos naturais, são unidades que garantem a presença humana respeitando seus direitos, organização e cultura, constituindo-se em importantes instrumentos destinados aos povos tradicionais (BENATTI, 2003, p. 175).

Ao lado das modalidades de assentamentos agroextrativistas, as unidades de conservação da natureza de uso direto, podem ser consideradas como regularização agroecológica (TRECCANI, 2006, p. 165) justamente por considerarem os aspectos culturais que envolvem o território, o uso e o manejo dos recursos naturais, bem como a necessidade de regularização das posses exercidas por esses povos.

Tal como já constava previsto na legislação ambiental, a Lei $n^{\circ} .9 .985 / 00$ dispõe que a RESEX é de domínio público, com uso concedido às populações extrativistas tradicionais (art. $18, \S 1^{\circ}$ ). A mesma regra de dominialidade pública se aplica às RDS (art. $20, \S 2^{\circ}$ e $\$ 3^{\circ}$ ). Nos dois casos, haverá a concessão de direito real de uso para a comunidade tradicional beneficiada (art. 23, Decreto n ${ }^{\circ}$. 4.340/02).

No caso das FLONAs, a Lei no. 9.985/00 prescreve que também são áreas de posse e domínio públicos, em que se admite a permanência de populações tradicionais que as habitam (art. $17, \S 1^{\circ}$ e $\S 2^{\circ}$ ). Embora siga a lógica similar às RESEX e RDS, no que tange ao instrumento

\footnotetext{
${ }^{22}$ Segundo o art. 18, da Lei no ${ }^{\circ}$ 9.985/00, a RESEX é uma área utilizada por populações extrativistas tradicionais, cuja subsistência baseia-se no extrativismo e, complementarmente, na agricultura de subsistência e na criação de animais de pequeno porte, e tem como objetivos básicos proteger os meios de vida e a cultura dessas populações, e assegurar o uso sustentável dos recursos naturais da unidade.

${ }^{23} \mathrm{O}$ art. 20, da Lei $\mathrm{n}^{\circ}$. 9.985/00 define a RDS como uma área natural que abriga populações tradicionais, cuja existência baseia-se em sistemas sustentáveis de exploração dos recursos naturais, desenvolvidos ao longo de gerações e adaptados às condições ecológicas locais e que desempenham um papel fundamental na proteção da natureza e na manutenção da diversidade biológica.

${ }^{24} \mathrm{O}$ art. 17 da Lei $\mathrm{n}^{\circ}$. 9.985/00 define a FLONA como área com cobertura florestal de espécies predominantemente nativas e tendo como objetivo básico o uso múltiplo sustentável dos recursos florestais e a pesquisa científica, com ênfase em métodos para exploração sustentável de florestas nativas.
} 
de regularização concedido, a FLONAs não foram concebidas com o objetivo maior de garantir a posse de comunidades tradicionais, embora a permanência seja admitida por lei.

No que tange à destinação das áreas ocupadas por povos tradicionais dentro das florestas públicas, existem normas específicas na Lei de Gestão de Florestas Públicas (Lei nº 11.284, de 02 março de 2006). A norma indica a criação de RESEX ou RDS para essas áreas, bem como a concessão de uso através de assentamentos ambientalmente diferenciados ou ainda, a regularização através de CDRU na FLONA (art. $6^{\circ}, \S 3^{\circ}$ ).

\section{TERRITÓRIOS QUILOMBOLAS}

As comunidades quilombolas no Brasil, aliadas aos movimentos socioambientalistas e dos povos da floresta que lutavam pelo reconhecimento de seus territórios, lograram importante conquista com a constitucionalização de seu direito territorial. O art. 68 do ADCT da CF/88 dispõe que aos remanescentes das comunidades dos quilombos que estejam ocupando suas terras é reconhecida a propriedade definitiva, devendo o Estado emitir-lhes os títulos respectivos.

O significado atual da expressão "remanescentes de quilombos" está muito longe de coincidir com a ideia de quilombos formados por escravos fugidos, guerreiros, isolados e autossuficientes. A comparação ao Quilombo de Palmares, por exemplo, não representa um modelo único definidor da história dos quilombos (TRECCANI, 2006, p. 145).

Sendo assim, ensina Treccani (2006, p. 146):

A nova definição deve ter como ponto de partida as situações socioculturais
específicas de cada comunidade, suas estruturas político-organizativas, seu conceito
de territorialidade que procurava garantir o acesso à terra e aos demais recursos
naturais e firmar sua identidade. Usar definições jurídicas que têm sua origem em
categorias alheias à prática quilombola, só trará prejuízo para os remanescentes.

A demarcação das terras tradicionalmente ocupadas ${ }^{25}$ por comunidades remanescentes de quilombos deve considerar, portanto, a continuidade de sua reprodução física e cultural, apoiados em seus próprios usos e costumes, respeitando-se sua forma de apossamento particular que também se expressa no conceito de posse agroecológica (BENATTI, 2003, p. 201).

Benatti (2003, p. 203) destaca que o reconhecimento dos direitos territoriais quilombolas, em sede constitucional, introduz importantes elementos jurídicos como a

\footnotetext{
${ }^{25}$ Almeida (2010) considera que são terras tradicionalmente ocupadas as terras indígenas, as terras de comunidades remanescentes de quilombos, bem como as áreas de uso comum voltadas para o extrativismo, a pesca, a pequena agricultura e o pastoreiro, dos povos da floresta e demais povos tradicionais.
} 
incorporação de conceitos étnicos e culturais para a demarcação da terra, além da titulação coletiva da terra, em prol da comunidade quilombola, e não de um núcleo familiar.

Nesse modelo de titulação, as comunidades devem constituir associações legalmente reconhecidas, que passam a exercer a representação, dos associados que a integram ${ }^{26}$. Serão, assim, os regimentos internos das associações que irão determinar como se dará o uso da terra e dos demais recursos naturais (TRECCANI, 2006, p. 167).

Os remanescentes de quilombo são comunidades camponesas tal como os demais povos e comunidades tradicionais que têm sua "origem nos laços rituais, de parentesco e de cooperação econômica e política" (BENATTI, 2003, p. 204). Apesar dos aspectos específicos próprios de cada grupo social que compõe o rol das comunidades tradicionais o modelo quilombola de uso da terra e demais recursos naturais também é similar (TRECCANI, 2006, p. 160).

Entretanto, a grande diferença é que as demais comunidades tradicionais "não têm a seu favor um mandamento constitucional explícito que obrigue o poder público a reconhecer-lhes a propriedade definitiva, emitindo o título da terra respectivo" (BENATTI, 2003, p. 204).

Sob o aspecto jurídico, a determinação do art. 68 do ADCT foi regulamentada pelo Decreto $n^{\circ} .4 .887^{27}$, de 20 de novembro de 2003, que dispõe sobre o procedimento para identificação, reconhecimento, delimitação, demarcação e titulação das terras ocupadas por remanescentes das comunidades dos quilombos ${ }^{28}$.

Na esfera federal, cabe ao Ministério do Desenvolvimento Agrário, através do INCRA, realizar esse processo que culmina com a demarcação e titulação das terras ocupadas pelos remanescentes das comunidades dos quilombos (art. $3^{\circ}$, Decreto $n^{\circ} .4 .887 / 03$ ). A Fundação Cultural Palmares, vinculada ao Ministério da Cultura, exerce a função de gerenciadora do Cadastro Geral onde são inscritos os documentos referentes à autodefinição ${ }^{29}$ das comunidades (art. $3^{\circ}, \S 4^{\circ}$, Decreto $n^{\circ} .4 .887 / 03$ ).

\footnotetext{
${ }^{26}$ Trata-se de uma dinâmica similar às associações que assinam contrato de concessão de uso das unidades de conservação de uso direto (TRECCANI, 2006, p. 166).

${ }^{27}$ Nos termos do art. $2^{\circ}$, do Decreto ${ }^{\circ} .4 .887 / 03$, consideram-se remanescentes das comunidades dos quilombos, os grupos étnico-raciais, segundo critérios de auto-atribuição, com trajetória histórica própria, dotados de relações territoriais específicas, com presunção de ancestralidade negra relacionada com a resistência à opressão histórica sofrida.

${ }^{28}$ Em 25 de junho de 2004 foi proposta Ação Direta de Inconstitucionalidade nº 3.239 pelo Partido Frente Liberal (atual DEM) contra o Decreto $n^{\circ}$. 4.887/03. Essa ação trata-se de apenas uma das chamadas "agroestratégias" do setor do agronegócio brasileiro, que buscam enfraquecer direitos territoriais e étnicos conquistados nos últimos anos no país (ALMEIDA, 2011, p. 30).

${ }^{29}$ Fruto da pressão dos movimentos quilombolas e da incorporação da Convenção no ${ }^{\circ} 169$ da OIT ao ordenamento jurídico brasileiro, o autorreconhecimento é elemento fundamental na política de reconhecimento dos territórios quilombolas (TRECCANI, 2006, p. 150).
} 
Administrativamente, é a Instrução Normativa $n^{\circ} .57$, de 20 de outubro de 2009, que regulamenta o procedimento no INCRA. Repetindo ditames básicos dispostos no Decreto $\mathrm{n}^{\circ}$. 4.887/03, a IN $\mathrm{n}^{\circ} .57$ considera remanescentes das comunidades dos quilombos os grupos étnico-raciais, segundo critérios de auto-definição, com trajetória histórica própria, dotados de relações territoriais específicas, com presunção de ancestralidade negra relacionada com a resistência à opressão histórica sofrida (art. $3^{\circ}$ ), sendo as terras por eles ocupadas definidas como toda a terra utilizada para a garantia de sua reprodução física, social, econômica e cultural $\left(\operatorname{art.} 4^{\circ}\right)$.

Quanto ao processo de titulação, considerando que o art. 68 do ADCT tem como sujeito um grupo social e não um conjunto de indivíduos (TRECCANI, 2006, p. 147), o art. 24 da IN $\mathrm{n}^{\circ} .57$ dispõe que a titulação se dará mediante a outorga de título coletivo e pró-indiviso à comunidade, em nome de sua associação legalmente constituída, sem nenhum ônus financeiro, com obrigatória inserção de cláusula de inalienabilidade, imprescritibilidade e de impenhorabilidade, devendo ser registrado no cartório competente. Trata-se de um título de reconhecimento de domínio, isto é, que garante a propriedade coletiva para a comunidade ${ }^{30}$.

Hoje, a competência do INCRA em relação aos territórios quilombolas limita-se à titulação, já que há o reconhecimento do domínio das comunidades. Mas, no passado, antes da regulamentação do art. 68, ADCT, via Decreto $n^{\circ} .4 .887 / 03$, o órgão fundiário federal criou projetos de assentamentos especiais para atender à demanda quilombola. No Estado do Pará foram criados, entre o período de 1995 a 2001, sete assentamentos especiais quilombolas, que até hoje integram os dados da reforma agrária disponíveis na base de dados do INCRA.

\section{MOdALIdAdES ESTAdUAis E A POLÍtica FUNDiÁRia NO ESTAdo DO PARÁ: ASSENTAMENTOS, UNIDADES DE CONSERVAÇÃO E TERRITÓRIOS QUILOMBOLAS}

Os Estados da federação também possuem competência para estabelecer sua própria política fundiária, pois, por força constitucional também são detentores de terras e bens públicos $^{31}$. Como já visto, a União tem competência exclusiva para se valer da desapropriação

\footnotetext{
${ }^{30}$ Em razão disso, no que tange à gestão de suas terras, Benatti (2011, p. 102) destaca que no caso dos remanescentes das comunidades dos quilombos, por ser reconhecido o domínio pleno, há autoadministração e autogestão das áreas. Já no caso das RESEX, RDS e assentamentos agroextrativistas, como a terra é de domínio público, o uso e manejo do recursos naturais pertencem à comunidade, mas com a administração partilhada com o poder público.

${ }^{31} \mathrm{O}$ art. da $\mathrm{CF} / 88$ estabelece que se incluem entre os bens dos Estados: as águas superficiais ou subterrâneas, fluentes, emergentes e em depósito, ressalvadas, neste caso, na forma da lei, as decorrentes de obras da União; as áreas, nas ilhas oceânicas e costeiras, que estiverem no seu domínio, excluídas aquelas sob domínio da União,
} 
para fins de reforma agrária. Entretanto, isso não impede a criação de assentamentos por parte dos Estado mediante a destinação de suas terras públicas.

Da mesma forma, a instituição de unidades de conservação da natureza é de competência constitucional comum ${ }^{32}$ entre as três esferas públicas: União, Estados e Municípios. Logo, os Estados, através de suas próprias políticas de meio ambiente e de seus órgãos ambientais podem criar RESEX, RDS e Florestas Estaduais.

O mesmo é válido no que tange aos territórios quilombolas. Caso as comunidades quilombolas exerçam sua posse em terras públicas estaduais, ou em áreas privadas, os Estados podem destinar as áreas públicas para o reconhecimento da propriedade coletiva quilombola, bem como valer-se do instrumento da desapropriação para efetivar suas ações.

Como já ressaltado, a Norma de Execução INCRA nº 69/08 indica os projetos de Reforma Agrária que são reconhecidos pelo poder público para integrarem o Programa Nacional de Reforma Agrária, categoria em que estão inseridos os projetos criados pelos Estados e Municípios.

No caso específico do Estado do Pará, a Constituição Estadual promulgada em 05 de outubro de 1989, estabelece entre os seus artigos 239 a 244 a Política Agrícola, Agrária e Fundiária Paraense. Nos termos do art. 239, essa política levará em conta, preferencialmente, dentre outras questões: a compatibilização das ações e metas do Plano Nacional de Reforma Agrária; a destinação para assentamentos agrícolas ou para proteção ambiental das terras públicas e devolutas discriminadas, na área rural.

É prevista ainda a transferência das terras públicas do Estado do Pará a pessoas físicas ou jurídicas, inclusive de caráter comunitário, ou qualquer forma associativa de trabalhadores rurais, através de alienação gratuita ou onerosa, ou concessão de uso, precedida de demarcação oficial, bem como a elaboração de projetos de assentamento de trabalhadores rurais, organizados em unidades cooperativas ou associativas.

No art. 255 da Constituição Estadual que trata da defesa, conservação, preservação e controle do meio ambiente está disposto que cabe ao Estado criar unidades de conservação da natureza, de acordo com as diversas categorias de manejo, implantando-as e mantendo-as com os serviços indispensáveis às suas finalidades.

Municípios ou terceiros; as ilhas fluviais e lacustres não pertencentes à União; as terras devolutas não compreendidas entre as da União.

${ }^{32} \mathrm{O}$ art. $225, \S 1^{\circ}$, inciso III dispõe que cabe ao Poder Público definir, em todas as unidades da Federação, espaços territoriais e seus componentes a serem especialmente protegidos. Regulamentando o comando constitucional, a Lei n ${ }^{\circ}$. 9.985/00 prescreve que o Sistema Nacional de Unidades de Conservação da Natureza - SNUC é constituído pelo conjunto das unidades de conservação federais, estaduais e municipais (art. $3^{\circ}$ ). 
Repetindo o comando da CF/88, o art. 322 da Carta Estadual, também prescreve que aos remanescentes das comunidades dos quilombos que estejam ocupando suas terras, é reconhecida a propriedade definitiva, devendo o Estado emitir-lhes títulos respectivos.

Em 24 de junho de 1994 foi editada a Política Agrícola, Agrária e Fundiária Estadual, por meio da Lei $\mathrm{n}^{\circ}$. 5.849 que sem seu art. 35 estabelece que são prioridades da ação fundiária do Estado do Pará o assentamento do pequeno produtor rural e a regularização das terras cultivadas pelos que nelas residem.

Diante dessas disposições é através do ITERPA (Instituto de Terras do Pará), autarquia estadual criada desde 1975, que o Pará desenvolve sua política agrária e fundiária. Segundo levantamentos de Brito e Cardoso Jr. (2015, p. 12) a execução da política agrária estadual abrange uma área de $18 \%$ a $24 \%$ do território paraense.

Em 24 de agosto de 2007, por meio da Norma de Execução nº. 01 do ITERPA foram criados: o Projeto Estadual de Assentamento Sustentável (PEAS) e o Projeto de Assentamento Estadual Agroextrativista (PEAEX). O Decreto Estadual nº. 2.280, de 24 de maio de 2010, os regula atualmente no âmbito do Programa Estadual de Assentamentos.

Ao lado dos PEAS e PEAEX, a legislação (art. $4^{\circ}$, Decreto Estadual n'. 2.280/10) indicou também, como modalidade de projeto de assentamento os territórios estaduais quilombolas (TEQ). Importante disposição, em consonância com a normativa do INCRA no que tange ao reconhecimento de projetos, consta no art. $4^{\circ}, \S 2^{\circ}$ :

Os beneficiários dos projetos de assentamentos estaduais, e dos territórios estaduais
quilombolas, serão incluídos entre os candidatos a beneficiários da reforma agrária no
âmbito do Plano Nacional de Reforma Agrária, fazendo jus aos mesmos benefícios de
crédito, infraestrutura e Assistência Técnica e Extensão Rural - ATER dos
beneficiários dos projetos de assentamento federais.

Os PEAS (art. $5^{\circ}$, Decreto Estadual $n^{\circ}$. 2.280/10) são áreas trabalhadas em regime de economia familiar que utilizam racionalmente os recursos naturais existentes, cumprindo a função socioeconômica e ambiental da terra. A destinação dessas áreas é feita mediante a celebração de contrato de concessão de uso em regime individual, em nome da unidade familiar, fazendo-se menção à área da parcela. Esse contrato é intransferível e inegociável, pelo prazo de 10 (dez) anos, podendo, após esse prazo, ser expedido Título Definitivo de Propriedade.

Os PEAEX (art. $6^{\circ}$, Decreto Estadual $n^{\circ}$. 2.280/10), por sua vez se destinam a populações que ocupam áreas dotadas de riquezas extrativas e pratiquem prioritariamente a exploração sustentável dos recursos naturais voltada para a subsistência e, complementarmente, se dediquem à agricultura familiar de subsistência, outras atividades de baixo impacto ambiental e à criação de animais de pequeno porte. Essas áreas serão de domínio público afetas 
ao interesse socioambiental relevante, com uso concedido às populações extrativistas e destinação mediante concessão de direito real de uso, em regime de uso comum, associativo ou cooperativista por prazo indeterminado.

Os TEQs (art. $7^{\circ}$, Decreto Estadual $n^{\circ}$. 2.280/10) são destinados aos remanescentes das comunidades de quilombos, cujos territórios tenham sido reconhecidos de propriedade dos mesmos e visa garantir o etnodesenvolvimento destas comunidades. A implantação dos TEQs levará em consideração as características territoriais, as formas de organização peculiares a cada grupo, preservando seus valores sociais e culturais, visando garantir a sustentabilidade ambiental e econômica destas comunidades.

No que tange às Unidades de Conservação, a Política Estadual de Meio Ambiente e o Sistema Estadual de Unidades de Conservação (SEUC) foram estabelecidos pela Lei ${ }^{\circ}$. 5.887, de 09 de maio de 1995, que devem seguir os parâmetros do SNUC, criado em 2000. Estão, atualmente, sob a jurisdição estadual, 21 unidades de conservação da natureza, incluindo, dentre as de uso sustentável, que admitem a presença de povos e comunidades tradicionais, duas RDS estaduais e quatro Florestas Estaduais ${ }^{33}$.

\section{OUTRAS MODALIDADES DE RECONHECIMENTO}

Também integram as categorias reconhecidas pelo INCRA, os Assentamentos Municipais (PAM), Projeto de Assentamento Casulo (PAC) e os Projetos de Reassentamentos de Barragem $(\mathrm{PRB})^{34}$.

Os PAMs são projetos de assentamento criados na esfera municipal, reconhecidos pelo INCRA, também por força da NE/INCRA nº 69/08, para fins de acesso aos benefícios da reforma agrária. Nessa modalidade, a obtenção da terra, a criação do projeto, seleção dos beneficiários e titulação cabe aos Municípios ${ }^{35}$, de acordo com a legislação própria.

Os PACs criados pela Portaria INCRA nº. 321, de 11 de setembro de 1997, atualizada pela Portaria INCRA n ${ }^{\circ}$. 740, de 07 de dezembro de 2012, são fruto de parceria do INCRA com o Poder Público Municipal, como modalidade de descentralização das ações do Programa de

\footnotetext{
${ }^{33}$ Segundo dados do Instituo Socioambiental (ISA), trata-se das RDS Alcobaça e Pucuruí-Ararão e das Florestas Estaduais de Faro, Iriri, Paru e Trombetas. Dados disponíveis em: <http://uc.socioambiental.org/uc/pesquisa/uf/PA>. Acesso 10 out 2016.

${ }^{34}$ Esse rol também inclui, segundo informações do INCRA, as áreas oriundas do antigo Programa Cédula da Terra (PCT), em que obtenção de terra se dava a partir da compra, e o Projeto de Assentamento de Fundo de Pasto. Como essas modalidades não foram implementadas nos estados da Amazônia Legal, não serão destacadas. Mais informações disponíveis em: <http://www.incra.gov.br/assentamentoscriacao>. Acesso 19 mai 2017.

35 Conforme informação no site do INCRA. Disponível em: <http://www.incra.gov.br/assentamentoscriacao〉. Acesso 19 mai 2017.
} 
Reforma Agrária, para formulação de políticas públicas direcionadas à agricultura familiar e empreendimentos familiares (Portaria $\mathrm{n}^{\circ} .740 / 12$ ).

Os Projetos Casulos ${ }^{36}$ são destinados para atividades economicamente viáveis, socialmente justas e ecologicamente sustentáveis, executadas pelas populações que ocupem áreas disponíveis na periferia dos núcleos urbanos, com o aproveitamento de mão-de-obra da própria família nas atividades econômicas (art. $1^{\circ}$ ). Nesses projetos, o domínio da área destinada poderá ser tanto do INCRA quanto do Município.

Os PRBs são destinados aos agricultores familiares atingidos pela construção de barragens de hidroelétricas. São assentamentos cuja implantação cabe aos empreendedores das obras para aproveitamento hidroelétrico, o que não impede o reconhecimento das famílias assentadas como clientes dos programas de reforma agrária ${ }^{37}$.

\section{CONSIDERAÇÕES FINAIS}

Segundo Sérgio Sauer (2013, p. 73) as mobilizações sociais de acesso à terra, seja por famílias de agricultores ou por comunidades tradicionais, contribuem para a afirmação e reafirmação da contemporaneidade das disputas territoriais. Tratam-se de lutas que não se restringem à questão agrária e que vão mais além: os atuais conflitos sociais no campo possuem dimensões culturais, identitárias e étnicas (ALMEIDA, 2011, p. 40).

Não se pode, portanto, restringir a causa somente aos povos tradicionais: a luta dos movimentos dos trabalhadores rurais sem-terra também possui essa vertente, pois a terra está intimamente ligada à construção da identidade social, como um "local de pertencimento, de construção real e simbólica do ser" (SAUER, 2005, p. 70).

A inserção desses instrumentos da Política Nacional de Reforma Agrária, especialmente os de regularização fundiária de povos e comunidades tradicionais, representa uma tendência na política de reforma agrária como um todo, consolidada após II PNRA.

Embora o presente artigo tenha um objetivo mais elucidativo sobre os atuais instrumentos, é necessário questionar os motivos dessa mudança e os seus efeitos na política fundiária como um todo. Como haverá mudança na estrutura fundiária do país? A reforma agrária passou a ter um conceito mais amplo ao se incluírem as demandas dos povos tradicionais? Quais os impactos para a Amazônia? São questões que ainda não possuem

\footnotetext{
${ }^{36}$ Segundo o art. $2^{\circ}$ da Portaria $n^{\circ} .740 / 12$, as Superintendências Regionais do Incra aprovarão os PCA, por meio de portaria de criação ou reconhecimento a ser publicada no Diário Oficial.

${ }^{37}$ Segundo consta na Portaria INCRA no. 687, de 28 de setembro de 2004.
} 
respostas prontas, mas que exigem uma análise aprofundada sobre as consequências jurídicas, sociais e políticas desse redirecionamento ${ }^{38}$.

\section{REFERÊNCIAS}

ALMEIDA, Alfredo Wagner Berno de. Reconfiguração das agroestratégias: novo capítulo da guerra ecológica. In: SAUER, Sergio; ALMEIDA, Wellington (orgs.). Terras e Territórios na Amazônia. Brasília: UNB/Abaré, 2011, p. 40.

BENATTI, José Heder. Propriedade comum na Amazônia: acesso e uso dos recursos naturais pelas populações tradicionais. In: SAUER, Sergio; ALMEIDA, Wellington (orgs.). Terras e Territórios na Amazônia. Brasília: UNB/Abaré, 2011, p. 93-113.

Posse agroecológica e manejo florestal. Curitiba: Juruá, 2003.

BERGAMASCO, Sônia Maria; NORDER, Luis A. Cabello. O que são assentamentos rurais? Coleção Primeiros Passos. São Paulo: Brasiliense, 1996.

BRITO, Brenda; CARDOSO JR, Dário. Regularização Fundiária no Pará: Afinal, qual o problema?. Belém: Instituto do Homem e Meio Ambiente da Amazônia/IMAZON, 2015. Disponível em: <www.imazon.org.br>. Acesso em 10.jan.2016.

CARVALHO, Horácio Martins de. Interação social e as possibilidades de coesão e de identidade social no cotidiano da vida social dos trabalhadores rurais nas áreas oficiais de reforma agrária no Brasil. Curitiba: Núcleo de Estudos Agrários e Desenvolvimento/NEAD, 1999. Disponível em: <http://www.dominiopublico.gov.br>. Acesso em 10.jan.2016.

GRAZIANO NETO, Francisco. A (difícil) interpretação da realidade agrária. In: SCHMIDT, Benício Viero; MARINHO, Danilo Nolasco C.; ROSA, Sueli L. Couto (Orgs.). Os assentamentos de Reforma Agrária no Brasil. Brasília: Editora Universidade de Brasília, 1998, p. 153-169.

LE TOURNEAU, François-Michel; BURSZTYN, Marcel. Assentamentos Rurais na Amazônia: contradições entre a Política Agrária e a Política Ambiental. In: Ambient.soc., Campinas, v. 13, n.1, jun. 2010, p. 111-130. Disponível em: 〈http://www.scielo.br/〉. Acesso em 20.mar.2015.

LIMA, Deborah; POZZOBON, Jorge. Amazônia Socioambiental. Sustentabilidade ecológica e diversidade social. In: Revista Estudos Avançados, vol. 19, nº. 54, 2005, p. 45-77.

MENEZES, Theresa Cristina Cardoso. Reservas Extrativistas no Amazonas: gênese, metamorfose e efeitos sociais. In: SAUER, Sergio; ALMEIDA, Wellington (Orgs.). Terras e Territórios na Amazônia. Brasília: Editora Universidade de Brasília, 2011, p. 345-360.

\footnotetext{
${ }^{38}$ Para uma análise sobre a questão, a partir dos dados da reforma agrária de 2004 a 2015, ver ROCHA, Ana Luisa Santos. Reforma Agrária na Amazônia: novas tendências, novos sujeitos e grandes desafios. Belém, Dissertação de Mestrado. Programa de Pós-Graduação em Direito. Universidade Federal do Pará, 2016.
} 
ROCHA, Ana Luisa Santos. Reforma Agrária na Amazônia: novas tendências, novos sujeitos e grandes desafios. Belém, Dissertação de Mestrado. Programa de Pós-Graduação em Direito. Universidade Federal do Pará, 2016.

ROCHA, Ibraim; TRECCANI, Girolamo Domenico; BENATTI, José Heder; HABER, Lilian Mendes; CHAVES, Rogério Arthur Friza. Manual de Direito Agrário Constitucional: lições de Direito Agroambiental. Belo Horizonte: Editora Fórum, 2015.

SAUER, Sérgio. O significado dos assentamentos de reforma agrária no Brasil. In: FRANÇA, Caio Galvão de; SPAROVEK, Gerd (coord.). Assentamentos em Debate. Brasília: MDA/NEAD, 2005, p. 57-74.

Agricultura Familiar versus agronegócio: a dinâmica sociopolítica do campo brasileiro. Brasília: Embrapa Informação Tecnológica, 2008.

Popular, 2010.

Terra e Modernidade: a reinvenção do campo brasileiro. São Paulo: Expressão

SANTILLI, Juliana. Socioambientalismo e novos direitos. São Paulo: Peirópolis, 2005, p. 142.

TRECCANI, Girolamo Domenico. Violência e grilagem: instrumentos de aquisição da propriedade da terra no Pará. Belém: UFPA: ITERPA, 2001.

Terras de quilombo: caminhos e entraves do processo de titulação. Belém: publicação própria, 2006, p. 131-211. 